\title{
Copper Cu 62-PTSM
}

National Cancer Institute

\section{Source}

National Cancer Institute. Copper Cu 62-PTSM. NCI Thesaurus. Code C113440.

A radioconjug ate consisting of a lipophilic, bioreductive copper(II)bis(thiosemicarbazone) complex, copper-pyruvaldehyde-bis(N4-methylthiosemicarbazone) (Cu-PTSM), linked to the beta-emitting, radioisotope copper $\mathrm{Cu} 62$, with potential perfusion and positron emitting tomography (PET) tumor imaging activities. Upon injection, the distribution of copper Cu 62-PTSM correlates with blood flow. This agent's high membrane permeability allows for rapid diffusion into cells. Once it enters the cell, 62Cu-PTSM is then reduced by the mitochondria, which prevents diffusion of the agent out of the cell. Upon PET imaging, tumor blood flow can be visualized and tumor perfusion can be assessed. Compared with other copper radionuclides, the short half-life of copper Cu 62 (9.7 minutes) reduces the amount of radiation a patient is subjected to and allows for several imaging studies to be performed. PTSM lacks selectivity for hypoxic cells. 